\title{
Nitroxidized-Albumin Advanced Glycation End Product and Rheumatoid Arthritis
}

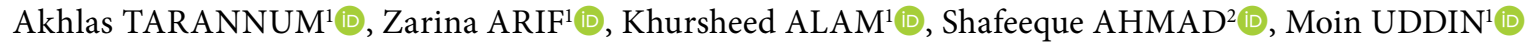 \\ Department of Biochemistry, Aligarh Muslim University, Jawaharlal Nehru Medical College, Aligarh, India \\ ${ }^{2}$ Department of Biochemistry, Al-Falah School of Medical Science \& Research Centre, AFU, Faridabad, Haryana, India
}

\begin{abstract}
Rheumatoid arthritis (RA) is an autoimmune disease whose major clinical consequence is inflammation of small joints and contiguous structures. Oxidative and nitrosative stress along with increased formation of advanced glycation end products (AGEs) play an important role in the disease process. Generation of reactive species during glycation of proteins further adds to the oxidative and nitrosative stress. Albumin, being the most abundant plasma protein, is frequently targeted by different oxidizing and nitrating agents, including peroxynitrite (OONO) anion. Albumin is also targeted and modified by dicarbonyl metabolites (glyoxal and methylglyoxal) which are formed in oxidative and non-oxidative processes during the synthesis of AGEs. The endogenously formed OONO and dicarbonyls may modify plasma albumin including those albumin that have travelled or migrated to synovial cells and caused nitration, oxidation, and glycation. These modifications may produce crosslinks, aggregate in albumin and confer immunogenicity. Simultaneous modification of albumin by OONO and dicarbonyls may generate nitroxidized-AGE-albumin which may persist in circulation for a longer duration compared to native albumin. Nitroxidized-AGE-albumin level (or serum autoantibodies against nitroxidized-AGE-albumin) along with other pre-clinical features may help predict the likely onset of RA.

Keywords: Advanced glycation end products, albumin, nitroxidation, rheumatoid arthritis.
\end{abstract}

Rheumatoid arthritis (RA) is a systemic autoimmune inflammatory disease of unknown etiology. The disease affects diarthrodial joints and is marked by abrasive synovitis, bone, and cartilage destruction and many other complications related to vascular, pulmonary, cognitive, and skeletal disorders. ${ }^{1}$ Around $1-2 \%$ of the population in developed countries are affected by RA, females being two to five times more likely to develop the disease. ${ }^{2}$ Despite the fact that the onset is more common during the later stages of life, it can show at any age.

Several autoantibodies have been associated with RA such as rheumatoid factor [autoantibody directed against the fragment crystallizable portion of immunoglobulin $\mathrm{G}(\mathrm{IgG})$ ], antiperinuclear factor (not easily detectable) and anti-citrullinated protein antibodies (ACPAs). ${ }^{3,4}$ RA patients are two to five times more prone to coronary artery disease, silent myocardial ischemia, sudden cardiac death, and overall cardiovascular mortality risk compared to general population. ${ }^{5}$ RA diminishes patients' practical capability (problems in carrying out regular activities like walking, dressing, use of hands and others), increases fatality rates (mainly due to cardiovascular complications), and results in poor health and social well-being. ${ }^{6}$

There is strong evidence that RA is a polygenic disease with various genetic and environmental causes that bring on an improper immunomodulation which results in an inflammatory process and consequently

Received: November 15, 2018 Accepted: January 10, 2019 Published online: April 22, 2019

Correspondence: Zarina Arif, MD. Department of Biochemistry, Aligarh Muslim University, Jawaharlal Nehru Medical College, 202002 Aligarh, India. Tel: 9897618082 e-mail: zarif66@gmail.com

\section{Citation:}

Tarannum A, Arif Z, Alam K, Ahmad S, Uddin M. Nitroxidized-albumin advanced glycation end product and rheumatoid arthritis. Arch Rheumatol 2019;34(4):461-475. 
deterioration of synovial structures. The major genetic risk factors for RA are class II major histocompatibility complex molecules human leukocyte antigen DR1 (HLA-DR1) (strongly associated with autoimmune diseases) and HLA-DR4. ${ }^{7}$ The shared epitope QKRAA (glutamine-lysine-arginine-alanine-alanine) or QRRAA (glutamine-arginine-argininealanine-alanine) is present in the third allelic hypervariable region of DR beta $(\beta)$ chains. It is the sensitivity epitope which inclines RA patients to the development of autoantibody (i.e. ACPA). ${ }^{7}$ Environmental factors also play an important role in the development and progression of RA. Cigarette smoking is the most common environmental cause which objectifies both the susceptibility as well as severity of disease. ${ }^{8} \mathrm{~A}$ variety of air pollutants (including particulate matter $<2.5 \mu \mathrm{m}$ in size [PM2.5], particulate matter $<10 \mu \mathrm{m}$ in size [PM10], sulfur dioxide, nitrogen dioxide $\left[\mathrm{NO}_{2}\right]$, carbon monoxide, and ozone) have also been demonstrated to be able to directly rouse up an inflammatory response. ${ }^{9}$ Several additional environmental causes like exposure to infectious agents and ionizing radiation and an imbalance in steroid hormones incline individuals to RA. ${ }^{8}$

Many studies propose the implications of oxidative and nitrosative stress and production of reactive dicarbonyl species (which ultimately form advanced glycation end products) in the pathogenesis of RA. Oxidative stress is a state in which the dynamic redox balance between oxidants and antioxidants is strongly switched towards oxidative potential leading to interruption of redox signaling and control and/or molecular damage. ${ }^{10}$ A parallel process is nitrosative stress which can be defined as the ratio of nitrosants to antioxidants as $>1$ with the participation of reactive nitrogen species (RNS). ${ }^{11}$ Similarly, advanced glycation end products (AGEs) formation and action is another parallel process linked to oxidative and/or nitrosative stress and inflammation. ${ }^{12}$

Albumin is the most abundant plasma protein of $66 \mathrm{kDa}$, its plasma concentration is between $3.5-5.0 \mathrm{~g} / \mathrm{dL}$ having a half-life of about 20 days. ${ }^{13}$ Albumin has many crucial physiological and pharmacological roles. It is not only involved in transporting metals, fatty acids, cholesterol, bile pigments, and drugs but it is also an essential component in the regulation of osmotic pressure and distribution of fluid between different compartments. It is a major and predominant antioxidant in plasma, a body compartment that is continuously exposed to oxidative stress. The antioxidant property of plasma is mainly (>70\%) due to albumin. ${ }^{14}$ The concentration of albumin usually remains very low in cerebrospinal, aqueous humor, and synovial and lung bronchoalveolar lining fluids compared with plasma. It is inflammation that enhances vascular permeability mostly through chemicals released by activated neutrophils. ${ }^{15}$ Albumin concentrations could be found enhanced in sites of inflammation, for the protein to exercise its various antioxidant properties. ${ }^{16}$

Albumin is also called a "sponge" or a "tramp steamer" of the circulation because it binds many types of molecules. In fact, many antioxidant activities of albumin result from its ligandbinding capacities. ${ }^{13}$ The flexibility of the albumin structure and its three-domain design provide a variety of binding sites that give it the ability to bind readily to ligands, such as metals ions, fatty acids, drugs, and also hormones. ${ }^{14}$ Albumin has only cysteine (Cys) 34 residue, which account for $80 \%$ of thiol (sulfhydryl [-SH]) in plasma because of high concentration of albumin in circulation. ${ }^{17}$ Albumin scavenges hydroxyl radicals through reduced Cys34. The $-\mathrm{SH}$ groups of albumin also act as important antioxidants against some RNS (peroxynitrite [OONO-]). ${ }^{18}$ All of the six methionine residues are oxidation-sensitive amino acids in albumin. ${ }^{14,18}$ Methionine can be easily oxidized to methionine sulfoxide by a wide variety of oxidants/nitrosants. ${ }^{19}$ The oxidationreduction cycle of methionine residues serves as an important reactive oxygen species (ROS)/ RNS scavenging system in organisms to protect proteins from extensive modifications.

\section{REACTIVE SPECIES AND DICARBONYL IN INFLAMMATION}

Inflammation is a common defense process of a healthy body in response to injury and infection. However, researches suggest that it may also be the central cause of many diseases. Inflammation may be acute or chronic. Acute inflammation is a healthy response while chronic 
inflammation is not involved in body's natural healing process. In fact, acute inflammatory response is a part of innate immune system characterized by secretion of various cytokines (interleukin 1 beta [IL-1 $\beta$ ], tumor necrosis factoralpha [TNF- $\alpha$ ], IL-6, and IL-15) and chemokines (IL-8) that enable recruitment of inflammatory cells to the site of infection. Inflammatory mediators (like histamine, platelet-activating factors, bradykinin, and thrombin) are released by inflammatory cells at the site of injury. ${ }^{20}$ The inflammatory cells (such as polymorphonuclear neutrophils) also produce ROS that are involved in the host-defense response. ${ }^{21}$ However, if the innate immune system is incapable of eliminating the pathogen, the situation is handed over to the adaptive immune system which activates specific $\mathrm{T}$ and $\mathrm{B}$ cells for pathogen elimination. ${ }^{20}$ If this process is prolonged or faulty, it develops to the chronic phase of inflammation that is linked with various diseases like that of the heart and RA. ${ }^{21}$

Both $\mathrm{B}$ and $\mathrm{T}$ cells guide the pathophysiology of RA with coordinated involvement of proinflammatory cytokines. The $\mathrm{B}$ cells stimulate secretion of pro-inflammatory cytokines such as TNF- $\alpha$ and IL- $6 .{ }^{22}$ The other functions of $\mathrm{B}$ cells include antigen presentation and activation of $\mathrm{T}$ cells, interaction with chemokines which promotes the formation of TNF- $\alpha$ which in turn activates macrophage. ${ }^{23}$ The activated $\mathrm{T}$ cells further support $\mathrm{B}$ cell activation and secretion of various cytokines which are responsible for synovial tissue inflammation. $\mathrm{T}$ cells also stimulate destructive chondrocyte and osteoclast activation. ${ }^{22}$ The CD4+ $\mathrm{T}$ cells are the major sub-type of $\mathrm{T}$ cells found to be linked with RA. In synovial tissue, $\mathrm{CD} 4+\mathrm{T}$ cells differentiate mainly into type 1 helper (Th1)-like effector cells which are responsible for the production of pro-inflammatory cytokines (such as interferon gamma [IFN- $\gamma$ ] and TNF- $\alpha$ ) and Th17. The Th17 (secretes IL-17 and IL-23) subtype of CD4+ T cells plays a central role in synovial inflammation which is followed by bone erosion. ${ }^{24}$ Both Th1 and Th17 sub-types play a vital role in propagating inflammation and tissue damage in RA.

Likewise, ROS function as a signaling molecule at physiological concentrations, regulating cell growth, differentiation, senescence, and apoptosis. However, prolonged ROS production is considered to be a key player in the progression of several inflammatory diseases. ${ }^{20}$ In some cases, ROS are generated as byproducts of metabolic processes either through the electron transport chain (ETC) in mitochondria and/or via the cytochrome P450. The other central source is the $\mathrm{NAD}(\mathrm{P}) \mathrm{H}$ oxidase [nicotinamide adenine dinucleotide (phosphate) oxidase] (a complex of enzymes that produces superoxide) which is present in a number of cells, particularly in the professional phagocytes and endothelial cells. These cells are key players in initiation and development of the inflammatory response. ${ }^{25}$

The inflammatory nature of RA indicates that oxidative stress is involved in this disease. ${ }^{26}$ Almost all chemical species which are formed by incomplete oxygen reduction comes under the category of ROS which are the most valuable class of radicals produced in living systems. ROS are highly reactive unstable chemical species that react with themselves and also with other molecules in order to gain stability. These are superoxide anion radical $\left(\mathrm{O}_{2}\right)$, hydroxyl radical $(\cdot \mathrm{OH})$, peroxyl radical and per hydroxyl radical and non-free radical species such as hydrogen peroxide $\left(\mathrm{H}_{2} \mathrm{O}_{2}\right)$ and singlet oxygen that are readily transformed into free radicals. ROS are formed during oxidative processes that normally occur at comparatively low levels in all cells and tissues and have both advantageous and deleterious effects. At low concentration, these are needed for sustaining redox status of the cell and for performing important cellular duties such as cell signaling, cytoskeletal regulation, cell growth, proliferation, differentiation, and apoptosis. They also provide a defense against attacking pathogens. ${ }^{27}$ Harmful effects of ROS are observed when there is an overproduction of these reactive species or their removal by antioxidant defense system gets disturbed. Overproduction of ROS may affect physiological processes and cause damage to cellular components such as lipids in cell membranes, proteins, and nucleic acids (Figure 1). ${ }^{28}$

Reactive oxygen species are also produced in the inflamed joints of RA patients either by macrophage and/or the activated neutrophils (the main cells of inflamed synovial fluid in RA) in the synovial cavity and may contribute to the maintenance of inflammation through the activation of inflammatory molecules, leading to the destruction of articular cartilage. ${ }^{29}$ Intense 

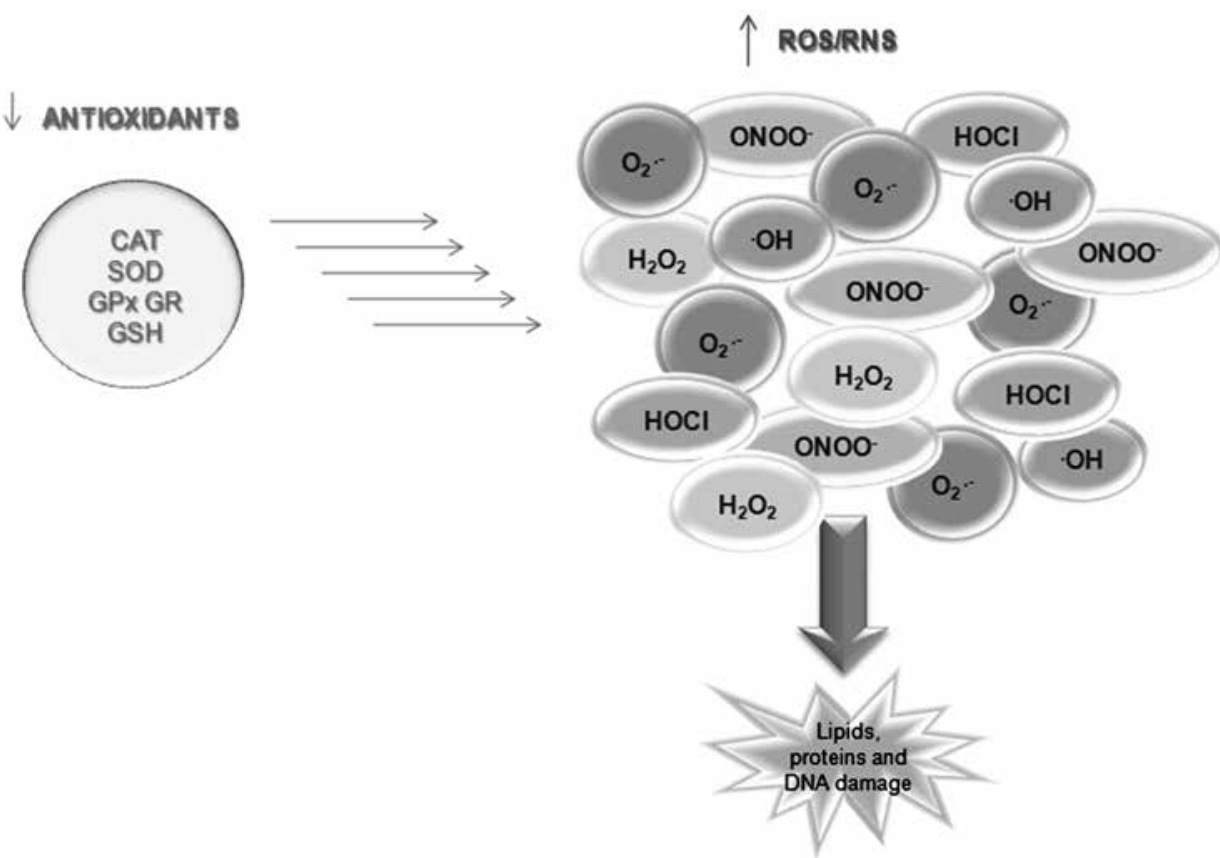

Figure 1. Scheme showing how an imbalance between reactive species and antioxidants can cause molecular damage.

CAT: Catalase; SOD: Superoxide dismutase; GPx GR: Glutathione peroxidase glutathione reductase; GSH: Glutathione; ROS: Reactive oxygen species; RNS: Reactive nitrogen species; $\mathrm{O}_{2}$ : Superoxide anion radical; $\mathrm{H}_{2} \mathrm{O}_{2}$ : Hydrogen peroxide; $\mathrm{HOCl}$ : Hypochlorous acid; OONO: Peroxynitrite; OH: Hydroxyl radical; DNA: Deoxyribonucleic acid.

production of inflammatory cytokines induces various enzymes such as $\mathrm{NAD}(\mathrm{P}) \mathrm{H}$ oxidase, nitric oxide synthase (NOS), myeloperoxidase (MPO), and eosinophil peroxidase. The NAD(P)H oxidase complex significantly contributes in ROS generation. Cytokines such as TNF- $\alpha$, IL- $1 \beta$, and IFN- $\gamma$ drive the activation of $\mathrm{NAD}(\mathrm{P}) \mathrm{H}$ oxidase complex which catalyzes the conversion of molecular oxygen into $\mathrm{O}_{2} \cdot{ }^{30}$ ROS are not only formed by the action of $\mathrm{NAD}(\mathrm{P}) \mathrm{H}$ oxidase but also by the process of oxidative phosphorylation in mitochondria. Complex I and complex III of the ETC are the important sites of ROS formation. Formation of ROS by complex I occurs in the matrix while ROS formation by complex III occurs at both sides of mitochondrial inner membrane. Uncoupling of electron transport within mitochondria increases the formation of $\mathrm{ROS}$ and $\mathrm{O}_{2}$ is produced inside mitochondria by one-electron reduction of oxygen. ${ }^{31}$ Some other enzymes such as xanthine oxidoreductase, cytochrome P450 monooxygenase system, and NOS also contribute in the ROS formation. ${ }^{25}$
Superoxide anion radical is one of the main culprits involved in inflammation noticeable in RA patients. $\mathrm{O}_{2}$, along with other oxygen and nitrogen radicals, deteriorate the elements of cartilage and extracellular matrix either directly or indirectly by decreasing the synthesis of matrix components (collagen and proteoglycans). ${ }^{32}$ The enzyme superoxide dismutase (SOD) reactive $\mathrm{O}_{2}-$ to $\mathrm{H}_{2} \mathrm{O}_{2}$ which is then converted into water by catalase (CAT) and glutathione reductase (GR) (Figure 2). In neutrophils, the enzyme MPO converts $\mathrm{H}_{2} \mathrm{O}_{2}$ into hypochlorous acid which further reacts with $\mathrm{H}_{2} \mathrm{O}_{2}$ to form singlet oxygen (a damaging radical). Also, $\mathrm{H}_{2} \mathrm{O}_{2}$ is converted to $\mathrm{OH}$ (in the presence of ferrous ion or other transition metals) via the Fenton's reaction. Hydroxyl reacts very quickly with proteins, lipids and nucleic acids, thereby causing injury to them and as a consequence results in severe outcome in the pathogenesis of RA.

Numerous studies have shown that IgG is also susceptible to oxidative modification which may induce aggregation, amino acid modification, and/or fragmentation. Degree of modification 


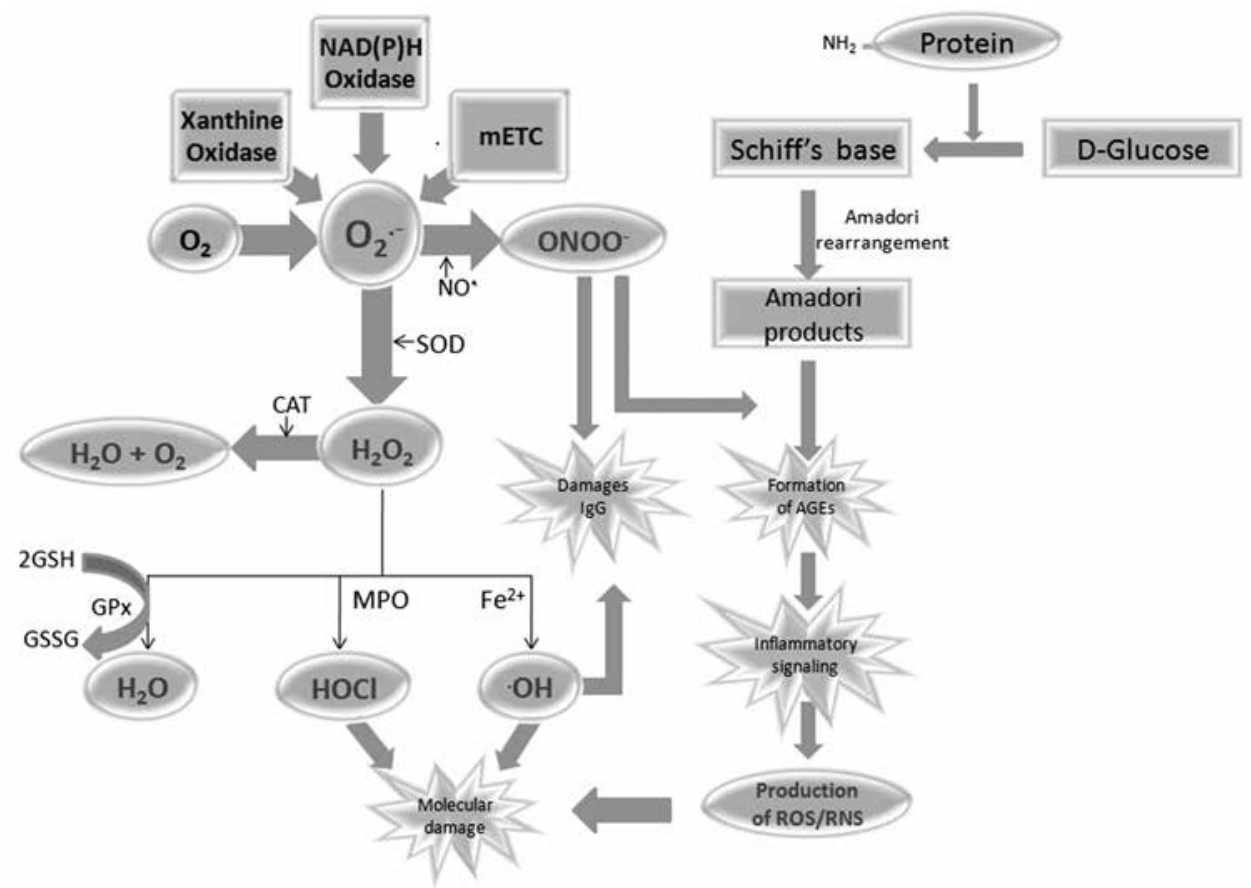

Figure 2. Different sources of reactive species in rheumatoid arthritis and generation of advanced glycation end products.

$\mathrm{NAD}(\mathrm{P}) \mathrm{H}$ : Nicotinamide adenine dinucleotide (phosphate) oxidase; mETC: Mitochondrial electron transport chain; $\mathrm{O}_{2}$ : Oxygen; $\mathrm{O}_{2}$ : Superoxide anion radical; OONO: Peroxynitrite; NO: Nitric oxide; SOD: Superoxide dismutase; CAT: Catalase; $\mathrm{H}_{2} \mathrm{O}_{2}$ : Hydrogen peroxide; GSH: Glutathione; GPx: Glutathione peroxidase; GSSG: Oxidized glutathione or glutathione disulphide; MPO: Myeloperoxidase; $\mathrm{Fe}^{2+}$ : Ferric iron; $\mathrm{H}_{2} \mathrm{O}$ : Water; $\mathrm{HOCl}$ : Hypochlorous acid; IgG: Immunoglobulin G; OH: Hydroxyl radical; $\mathrm{NH}_{2}$ : Amino group; AGES: Advanced glycation end products; ROS: Reactive oxygen species; RNS: Reactive nitrogen species.

and/or damage may differ according to the nature of reactive species involved. $\mathrm{OH}$ cause aggregation of $\mathrm{IgG}$, whereas $\mathrm{OH}_{2}$ species may induce chemical modification without aggregation; both have been implicated in the pathogenesis of RA. ${ }^{33}$ In addition to ROS, RNS have also been stated to be mediators of tissue destruction in RA patients. Nitric oxide (NO), $\mathrm{NO}_{2}$, and $\mathrm{OONO}^{-}$symbolize the most important RNS. The inducible NOS which has been reported to be overproduced in RA produce NO by the deamination of L-arginine. ${ }^{34}$ The major producers of NO are cartilage and inflammatory synovium, chondrocytes being the primary producer among the cells of articular joints. It contributes to cartilage degradation by activating metalloproteases and by restricting the synthesis of proteoglycans. ${ }^{32}$ When generation of $\mathrm{NO}$ and $\mathrm{O}_{2}$ happens simultaneously, it triggers the formation of a toxic reaction product, OONO anion. NOS produces both $\mathrm{NO}$ and $\mathrm{O}_{2}$ when cellular concentration of arginine is very low, which results in generation of extremely active OONO which contribute to cytotoxicity. ${ }^{34}$

Peroxynitrite anion, which is a potent and versatile oxidizing and nitrating agent, is generated under several pathological conditions (ischemia, reperfusion, injury, inflammation, and sepsis) by various metabolic reactions. ${ }^{35,36}$ Proinflammatory cytokines (IL-1 $\beta$ and TNF- $\alpha$ ) increase NOS activity that induces the generation of $\mathrm{OONO}^{-37}$ It is a quite stable and an essential species in mediating the toxicity of $\mathrm{O}_{2}$ and $\mathrm{NO}^{38}$ It is not a free radical by chemical nature but still a mediator of toxicity in inflammatory processes with strong oxidizing and nitrating properties toward biological molecules, including -SHs, ascorbate, lipids, amino acids, and nucleotides. ${ }^{39,40}$ It can also cause strand breaks in deoxyribonucleic acid (DNA). ${ }^{41}$ Free or protein-bound tyrosine residues (and other phenolics) can be nitrated by OONO to form 3-nitrotyrosine (interfere with phosphorylation/ dephosphorylation signaling) which has been 
used as a probe for RNS generation and a specific marker of $\mathrm{OONO}^{-}$both in vivo and in vitro. ${ }^{42} \mathrm{OONO}^{-}$is an important contributor to various forms of vascular, inflammatory, neurodegenerative, and autoimmune diseases. ${ }^{43}$ Multiple lines of evidence gave a strong proof that $\mathrm{OONO}^{-}$is actually produced in arthritis. ${ }^{44,45}$

The detrimental effect of OONO- may be seen when it acts on the cells and tissues, thereby causing protonation, and thus decrease in many antioxidants and -SH groups, oxidation of lipids and DNA damage. As - $\mathrm{SH}$ groups are decreased significantly, the redox balance in the glutathione (GSH) is switched more towards the oxidative and/or nitrosative stress. This unbalanced redox status of the GSH leads to activation of the nuclear factor kappa B (NF-kB) pathway, which in turn assists the transcription of various inflammatory mediators implicated in the pathogenesis of the disease. ${ }^{46}$ Various studies showed that AGEs are generated by reactive dicarbonyl species in synovial fluid of RA patients as a result of oxidative/nitrosative stress. ${ }^{47,48}$

Formation of AGEs from Maillard reaction is a series of non-enzymatic reactions that involve carbonyl groups of reducing sugars and amino groups of proteins, nucleic acids or phospholipids forming Schiff bases which is followed by Amadori rearrangement and glycoxidation of Amadori compounds induced by reactive oxygen and nitrogen species (Figure 3). ${ }^{49}$ This glycoxidation of Amadori products give rise to reactive 1, 2-dicarbonyl compounds (e.g. glyoxal). Autoxidations of sugars and other glycation intermediate also form 1, 2-dicarbonyl compounds (e.g. methylglyoxal). ${ }^{49}$ These reactive dicarbonyl metabolites are physiological glycating agents that react mostly with amino groups of protein which may undergo further glycoxidation resulting in protein crosslinks and modifications forming AGEs. ${ }^{49}$ AGEs also have the ability of cross-linking of proteins and reaction with receptor for AGEs (RAGE).

The RAGE, present on the surface of lymphocytes, leukocytes, macrophages, smooth muscle cells, and endothelial cells etc. ${ }^{50}$ has been found to influence cell survival, cell proliferation, oxidative stress as well as inflammatory responses. These effects are a result of interaction between RAGE and AGEs as reported in a limited number of studies. ${ }^{51,52}$ Ligand bound RAGE activation also induces cytokines production which is followed by upregulation of multiple signaling pathways. Also, it drives NF- $\mathrm{kB}$ expression which is followed by upregulation of inflammatory markers (TNF- $\alpha$ and TNF- $\beta$, IL- 1, IL- 6 and IL- 8, IFN- $\gamma$ ) and cell adhesion molecules, and subsequently recruitment

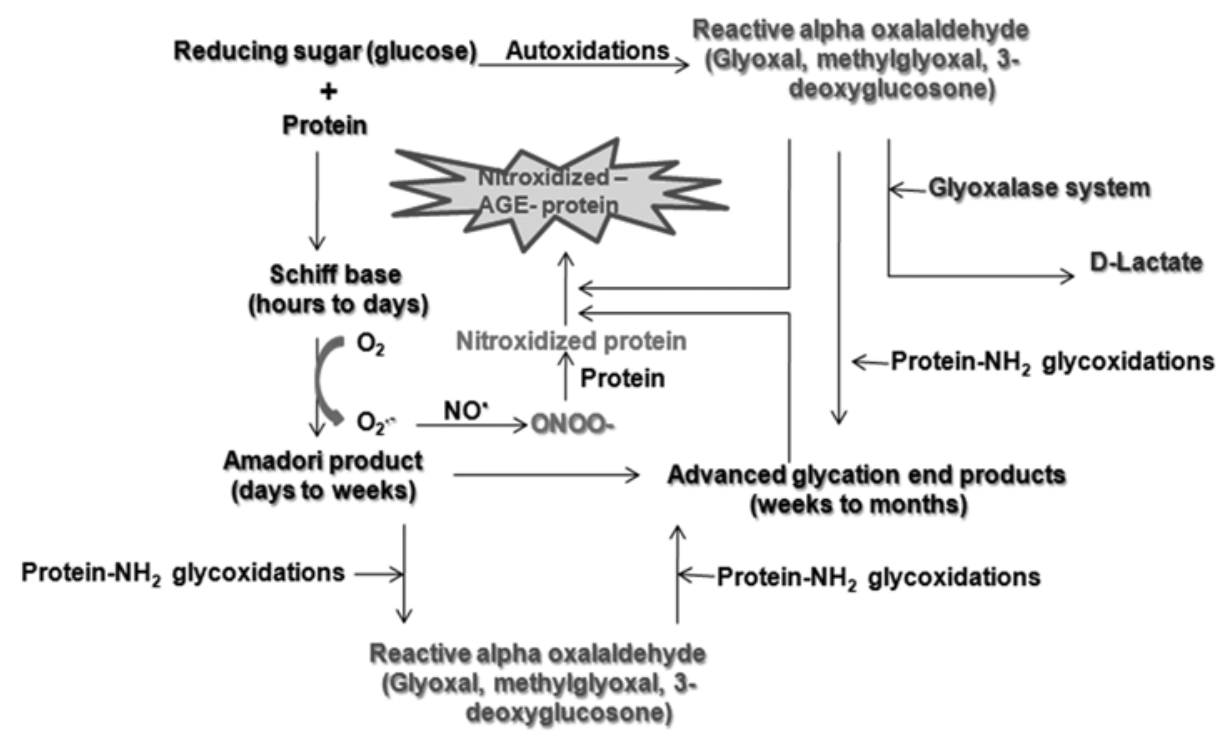

Figure 3. Formation of reactive dicarbonyl metabolites and advanced glycation end products in rheumatoid arthritis.

$\mathrm{O}_{2}$ : Oxygen; $\mathrm{O}_{2}$ : Superoxide anion radical; NO: Nitric oxide; OONO: Peroxynitrite; AGE: Advanced glycation end product; $\mathrm{NH}_{2}$ : Amino group. 
of inflammatory cells at the site of inflammation. ${ }^{21}$ many of which are central for inflammation. A high level of circulating TNF- $\alpha$ was reported to be a crucial mediator in RAGE/AGE linked effects and NF-KB signaling pathway. ${ }^{53}$ Also, the secreted IL-6 elicits an inflammatory response through IL-6 receptors found in inflammatory cells. $^{21}$ It was also reported that S100B-RAGE interaction stimulates pro-inflammatory responses in addition to ROS production in monocytes/macrophages. ${ }^{54}$ Furthermore, the interaction of $\mathrm{S} 100 \mathrm{~B}$ and RAGE upregulates cyclooxygenase-2 (COX-2) enzyme expression which has been implicated in the pathogenesis of several inflammatory diseases. ${ }^{55}$ The COX-2 is responsible for formation of prostanoids such as thromboxane and prostaglandins. However, increased prostaglandins level is considered as a marker of oxidative stress. ${ }^{56}$ The triggering of inflammatory effector mechanisms (generation of cytokines and chemokines, and expression of cell adhesion molecules) mediated by the AGE-RAGE interaction engages multiple intracellular signal transduction pathways, including p21ras, mitogen-activated protein kinase (MAPK), phosphatidylinositol-3 kinase (PI3-K), cdc42/Rac, Janus kinase/signal transducers and activators of transcription, NADPH oxidase, and others. ${ }^{57-60}$

The AGE-RAGE interaction drives the activation of MAPK and PI3-K pathways which lead to activation of transcription factor NF- $\kappa B .{ }^{60}$ The levels of these dicarbonyl metabolites (methylglyoxal and glyoxal) that contribute to protein glycation and AGEs formation are checked by glyoxalase system which provides an enzymatic defense against glycation. ${ }^{61}$ However, activation of NF- $\mathrm{kB}$ signaling pathway induced by oxidative and/or nitrosative stress as well as by AGE-RAGE interaction down regulates expression of gloxalase 1 enzyme of the glyoxalase system. ${ }^{62}$ It is thus plausible that glyoxal and methylglyoxal derived AGEs may increase in RA through oxidative/nitrosative stress and RAGE activated down regulation of glyoxalase 1 . During AGEs formation, the equilibrium between prooxidants

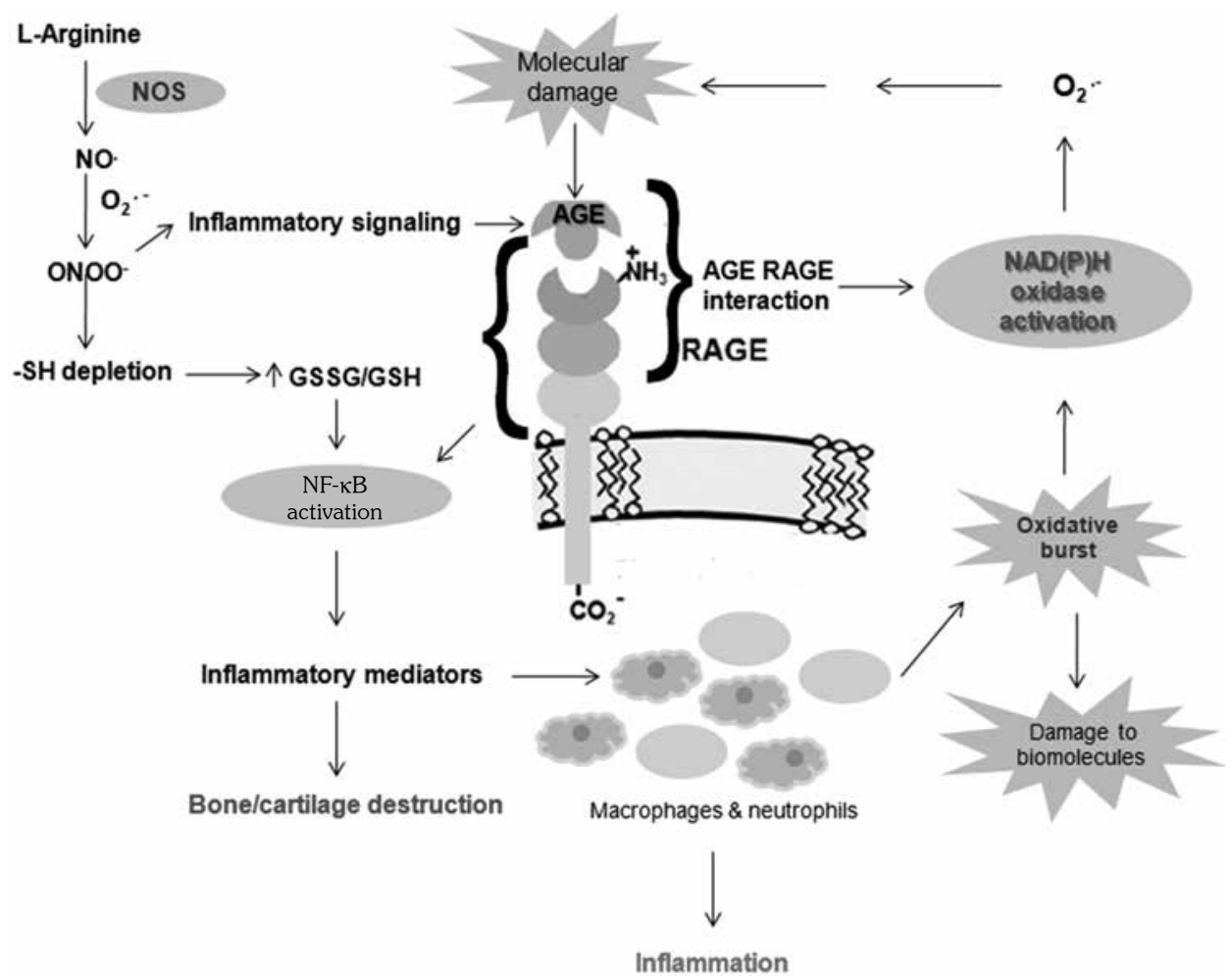

Figure 4. Outline of oxidative and nitrosative events in rheumatoid arthritis.

NOS: Nitric oxide synthase; NO: Nitric oxide; $\mathrm{O}_{2}$ : Superoxide anion radical; OONO: Peroxynitrite; -SH: Sulfhydryl; GSSG/GSH: Oxidized glutathione or glutathione disulphide/glutathione; NF-kB: Nuclear factor kappa B; AGE: Advanced glycation end product; $\mathrm{NH}_{3}$ : Anilinium ion; $\mathrm{CO}_{2}$ : Carbon dioxide; RAGE: Receptor for advanced glycation end product; $\mathrm{NAD}(\mathrm{P}) \mathrm{H}$ : Nicotinamide adenine dinucleotide (phosphate) oxidase. 
and antioxidants switches to the former that leads to a marked elevation in levels of ROS and RNS which in turn lead to oxidation/nitration of proteins, lipids, and nucleic acids. Normally, damaged proteins are eliminated by the $20 \mathrm{~S}$ proteasome of the ubiquitin-proteasome system (UPS). ${ }^{63}$ However, formation of crosslinked proteins causes UPS inhibition. AGEs can block the proteasomal core entry due to their bulky structure. ${ }^{63}$ The resulting decrease in proteolytic activity increases the level of oxidized and/or nitrosylated and damaged proteins. ${ }^{63}$ Oxidative/nitrosative stress and inflammation also lead to an increased formation of AGEs. ${ }^{64}$ It is because increased levels of oxidants/nitrosants support the oxidation of lipids and glucose, resulting in the increased production of AGEs. As a result, an elevation in levels of AGEs occurs that promote the formations of reactive oxygen and nitrogen species which consecutively induce further formation of AGEs. Morover, AGERAGE interaction derived activation of NF- $\mathrm{KB}$ increases RAGE expression, which creates a positive feedback cycle that also enhances the production of many inflammatory mediators. Also, AGE-RAGE interaction activates $\mathrm{NAD}(\mathrm{P})$ $\mathrm{H}$ oxidase that further increases intracellular oxidative/nitrosative stress. The abrupt increase in oxidative/nitrosative stress by $\mathrm{NAD}(\mathrm{P}) \mathrm{H}$ oxidase (in response to AGE-RAGE interaction) will also activate NF- $\mathrm{KB}$, thereby resulting in the transcription of various inflammatory promoters involved in the pathogenesis of RA (Figure 4). ${ }^{65}$ Moreover, NF- $\mathrm{kB}$ driven expression of COX-2 induced by IL-1 $\beta$ has also been reported. ${ }^{66}$

\section{REACTIONS OF REACTIVE SPECIES AND DICARBONYL WITH BIOMOLECULES}

One of the main targets of these reactive species is lipids which are extremely susceptible due to the presence of multiple bonds in polyunsaturated fatty acids. Hydroperoxides have bad effects on cells either directly and/or indirectly through degradation to hydroxyl radicals. On reacting with transition metals (copper and iron), they produce highly reactive aldehydes like malondialdehyde (MDA) which damages cell membrane. ${ }^{67}$ In addition to MDA, lipid peroxidation also leads to the production of many other highly reactive aldehydes such as acrolein, 4-hydroxynonenal, and isolevuglandins. It causes deterioration of biological membrane functioning by diminishing its fluidity and inactivating membrane boundreceptors and enzymes. MDA has been reported as the most important biomarker of free radical induced lipid damage and oxidative/nitrosative stress. It was also suggested that lipid peroxidation markers can play role as surrogate markers for disease activity. ${ }^{68}$ Structure and functions of proteins can also be changed by reactive species induced modifications. Cysteine, histidine, methionine, proline, and tyrosine are some of the targets of protein oxidation. Glycoxidation reaction with lysine group or secondary reaction with product of lipid peroxidation (4-hydroxynonenal) forms protein carbonyls (a potential biomarker of oxidative stress). ${ }^{68}$ The $-\mathrm{SH}$ groups have a very crucial role in protecting the body's status of antioxidants which exist either freely or bound to proteins. They protect macromolecules against the deleterious effects of free radical induced damage by eliminating them and hence are the major antioxidants present in the body. They also perform an important role in proper folding of proteins, maintaining their stability as well as for membrane transport processes. ${ }^{69}$ - $\mathrm{SH}$ groups and sulphur containing amino acids are highly susceptible to ROS. Reactive species extract a hydrogen atom from cysteine residues to form a thiyl radical that cross-links with another thiyl radical forming disulfide bridges. ${ }^{70}$ Several studies have shown that after a certain extent, further damage leads to formation of extensively crosslinked and aggregated products. These crosslinked and aggregated proteins are not only poor substrates for degradation, but also inhibit proteases that degrade other modified proteins.

In inflamed RA joints, levels of high mobility group box chromosomal protein-1 and S100A12 (RAGEs in RA) are extremely increased. ${ }^{71} \mathrm{RA}$ synovial tissue endothelium also shows increased levels of RAGE and proinflammatory adhesion molecules. ${ }^{72}$ Also, macrophages settled from RA synovial fluid cells contain extensive amounts of RAGE protein. There is an infiltration of synovial tissue by various inflammatory mediators which are characterized by presence of CD68+ macrophages on RAGE antigen, increased levels of TNF- $\alpha$, cytokine, and IL-1 at the inflammatory 
site which leads to progression of disease. ${ }^{73}$ In addition to glucose, reactive carbonyl intermediates derived from Maillard reaction (3-deoxyglucosone) or products of autoxidation of sugars (glyoxal and methylglyoxal) and lipid peroxidation (MDA) causes chemical modification of proteins. ${ }^{74,75}$ Generation of 3-deoxyglucosone is non-oxidative while other reactive carbonyl compounds are closely linked to oxidative processes. ${ }^{76}$ Proteins that are susceptible to modification and functional impairment by dicarbonyl metabolites (methylglyoxal) are called dicarbonyl proteome (e.g. albumin). Methylglyoxal modification of protein is particularly damaging because modification is directed mainly to arginine residues (and/or lysine residues) which have the greatest possibility for location at the functional sites of protein. ${ }^{77}$ Methylglyoxal increases in oxidative/nitrosative stress and contributes to oxidants/nitrosants induced cytotoxicity. Several studies have shown that low density lipoproteins (LDLs) and proteins can be modified by this dicarbonyl metabolite. Also, increased methylglyoxal modification of mitochondrial proteins may also induce oxidative stress. ${ }^{77}$ AGEs are inducible by oxidative/nitrosative stress and induce oxidative/nitrosative stress. $\mathrm{N}$ epsilon-(carboxymethyl)lysine (CML), an AGE, is a product of both lipid peroxidation and glycoxidation..$^{78,79} \mathrm{OONO}^{-}$is found to induce CML formation not only by oxidative cleavage of Amadori product but also by generation of reactive alpha oxoaldehydes from glucose inducing protein modification. ${ }^{80} \mathrm{OONO}^{-}$was also shown to increase NF- $\mathrm{\kappa B}$ via proteasomal degradation of inhibitor of NF- $\kappa \mathrm{B} .{ }^{81}$

\section{HANDLING OF REACTIVE SPECIES AND DICARBONYLS}

In order to suppress the damaging effect of pro-oxidants/nitrosants, the body has an antioxidant defense system that guards the cellular system from oxidative/nitrosative damage. An antioxidant may be defined as a substance that, even if present at low concentrations, significantly prevents or delays the oxidation/nitration of its substrates. A few enzymes that are involved in the neutralization or elimination of reactive species are SOD, glutathione peroxidase and CAT,
GR, glutathione S-transferase, thioredoxin reductase, and heme oxygenase. ${ }^{82}$ There are also a few non-enzymatic antioxidants like vitamins (A, C, and E), carotenoids, flavonoids, GSH, and few antioxidant minerals like copper, ferritin, manganese, selenium, and zinc. ${ }^{83}$ Furthermore, formation of dicarbonyl intermediates in living system is checked by glyoxalase system. It is composed of two enzymes, glyoxalase 1 and glyoxalase 2, with a catalytic amount of GSH. It converts methylglyoxal to D lactate via an intermediate S-D-lactosyl GSH. Gloxalase 1 forms S-Dlactosyl GSH via isomerization of hemiacetal (instinctively formed from methylglyoxal and GSH). Gloxalase 2, a thiolesterase, hydrolyzes S-D-lactosyl GSH to D-lactate and reforms GSH utilized in glyoxalase 1 catalyzed step. ${ }^{84,85}$

\section{OXIDATIVE, NITROSATIVE AND DICARBONYL STRESS IN RHEUMATOID ARTHRITIS}

Oxidative and nitrosative stresses play crucial roles in the pathogenesis of RA. Numerous studies have shown that there is an opposite relationship between occurrence of RA and dietary consumption of antioxidants; ${ }^{86}$ dietary intake of antioxidants has been inversely related with inflammation in RA. Several factors are involved in the initiation of oxidative and nitrosative stress in the joints of RA patients. With its silent attack, there is usually no apparent joint swelling; however, acute development of RA occurs in $10 \%$ of the patients. ${ }^{87}$ As the condition worsens, there is a comparatively symmetrical inflammatory process in the joints, usually starting in the small joints of hands and feet, but any joint can be affected. Transient ischemia of the membrane develops due to the pressure created by the activity of inflamed joints. Joints of RA patients have much higher intra-articular pressure because of the fibrosis of capsule and swelling of membrane. This inflation in the pressure causes breakdown of the blood vessels thereby leading to ischemia-reperfusion injury in the joint which is also accountable for the release of copper and iron ions, both of which drive the production of free radicals. ${ }^{88}$ Studies have shown that there is a positive correlation between severity of the 
disease and oxidative/nitrosative stress in RA patients. ROS/RNS decreases the viscosity of the joints by depolymerizing hyaluronic acid. Hypo-responsiveness of $\mathrm{T}$ cells is induced by oxidative damage of hyaluronic acid through its effect on proteins and proteasomal degradation. ${ }^{88}$ Bone traction and cartilage damage also occur due to excess production of RNS. Enhanced lipid peroxidation has been stated in the erythrocytes, plasma, and synovial fluid of patients with RA. Formation of lipid peroxidation products, oxidation of LDLs, and increase in the protein carbonyl contents were reported in the synovial fluid and in tissues of RA patients. ${ }^{89,90}$ Oxidative damage in DNA, extracellular collagen, and cartilage have also been reported. Production of $\mathrm{NO}$ and $\mathrm{O}_{2}$ and therefore $\mathrm{OONO}^{-}$was found to be higher in RA patients compared to healthy controls. ${ }^{55}$

Rheumatoid arthritis patients generate AGEs (a byproduct of oxidative/nitrosative stress) as a result of neutrophils activation. A study demonstrated that blockade of RAGE suppressed clinical and histological evidence of arthritis indicating the role of AGEs in pathogenesis of RA. ${ }^{51}$ Formation of AGE is dependent on the concentration and reactivity of glucose, availability of AGE-precursors, i.e. dicarbonyl metabolites, and presence of free amino groups. Glyoxal and methylglyoxal derived AGEs may be increased in RA through RAGE activated down regulation of gloxalase $1 .^{61}$ Moreover, the effect of ROS and RNS on increased AGE formation has also been studied. Accumulation of AGEs has been shown in inflamed RA synovial tissue with RAGE antigen expression overlapping with the distribution of AGE epitopes. ${ }^{91}$ CML (an AGE) can also be used as a marker of oxidative stress. ${ }^{48}$ Its accumulation in RA synovial tissue might be the result of oxidative stress during local and systemic inflammation. Oxidative and nitrosative stress can transform inflammation into chronic disease due to the mutation of key regulatory genes caused by different metabolic changes. ${ }^{21}$ Several studies highlight the generation of neo-epitopes due to formation of AGEs, thereby, resulting in the generation of autoimmune response..$^{92,93}$ Elevated levels of pentosidine (an AGE) in serum and urine reflect the increased disease activity in RA patients. ${ }^{94}$ Pentosidine formation is accelerated by oxidative and nitrosative conditions indicating its implication in the disease process of RA..$^{94,95}$
These findings imply that AGEs production and nitrosative stress are mainly due to increased levels of reactive oxygen and nitrogen species and the decreased antioxidant property of the cells. This imbalance between antioxidant enzymes and ROS-meditated AGE formation stimulates further ROS and RNS generation (such as OONO) that leads to a vicious cycle of nitrosative stress and increased protein damage.

\section{ALBUMIN MODIFICATION BY REACTIVE SPECIES AND DICARBONYLS AND ROLE OF MODIFIED-ALBUMIN IN RHEUMATOID ARTHRITIS}

Oxidation, nitration, and glycation are nonenzymatic processes in tissues and body fluids which contribute to modification of cartilage and other proteins of the joints during development and progression of RA. ${ }^{96}$ Increased oxidative damage and nitration to proteins in RA are consequences of increased ROS and RNS formed in the oxidative burst of neutrophils and macrophages migration into the arthritic joint. ${ }^{97}$ Glycated proteins have also been implicated in initiation and progression of arthritis that is a result of oxidative and nitrosative stress driven glycoxidation in RA. ${ }^{98}$ Reactive dicarbonyl metabolites such as methylglyoxal, glyoxal, and 3-deoxyglucosone are important physiological glycating agents but they differ from glucose as their modification is directed mainly to guanidine group of arginine residues. ${ }^{99}$ Studies related to gene deletion and pharmacological activation of nuclear factor erythroid 2-related factor 2 (transcription factor which coordinates basal and inducible expression of enzymes that protect against oxidative/nitrosative stress and dicarbonyl glycation) support that oxidative and nitrosative damage and dicarbonyl glycation are key players in the initiation and progression of RA. ${ }^{62,100,101}$

Albumin (an antioxidant as well as a dicarbonyl proteome) is targeted by both reactive species and dicarbonyl metabolites and the concentration of modified protein is related to the severity of the disease. In the course of its long lifetime, an albumin molecule makes 15,000 passes through the circulation and can acquire some damage that influences its antioxidant 
properties. ${ }^{13}$ Reports showed that decreased antioxidant properties of impaired albumin may be connected to pathological situations correlated with diabetes mellitus, early occurrence of vascular complications, and autoimmune diseases, together with functional alterations of albumin. In this complicated pathology, albumin undergoes increased glycation. ${ }^{13}$ Albumin glycation led to a considerable deficit in its antioxidant characteristic with respect to copper mediated oxidation of LDL. ${ }^{13}$ In physiological conditions, $0.9 \%$ of the albumin is glycated by dicarbonyl metabolites; however, its level may increase in several pathological conditions. It was confirmed that gathering of $\mathrm{CML}$, a dominant antigenic AGE, was involved in tissue disorders, hyperglycemia, and inflammation. ${ }^{102}$ It was shown in a study that when glycated human serum albumin was incubated with OONO, CML formation was detected that increased with increasing concentrations of $\mathrm{OONO}^{-48}$ Another study pointed out that $\mathrm{OONO}^{-}$mediated $\mathrm{CML}$ formation may play an important role in the formation of AGEs and the pathogenesis of RA. ${ }^{80}$

It may also be speculated that OONO modified-HSA generate neo-epitopes produced by OONO- modification that creates biophysical and biochemical changes in the protein, which was confirmed by the generation of highly specific antibodies in an experimental animal study. ${ }^{103}$ Such antibodies against modified/damaged albumin have been reported in various diseases like diabetes mellitus, systemic lupus erythematosus, and other autoimmune diseases and in cancer. ${ }^{103}$ Many impairments in the antioxidant properties of albumin after glycation and/or oxidation and/or nitration are manifested and they are important in the pathogenesis of many diseases. ${ }^{104,105}$ OONOproduced during inflammatory conditions causes structural changes in albumin that has been trapped in synovial cells. ${ }^{106}$ The nitroxidizedalbumin is poorly susceptible to proteases and thus remains in circulation for a longer period than its native counterpart. This nitroxidized-albumin is considered foreign by immunoregulatory cells and they start producing antibodies against it. These autoantibodies are an indicator of the initiation and/or progression of RA. ${ }^{104}$

In conclusion, effective treatment of RA is limited due to failure of early diagnosis of the disease. Consequently, RA is typically diagnosed only after the damage to the joints has begun, a time at which remission of the disease is difficult. The thrust for sensitive biomarkers for RA has been the object of interesting research in the last few years. Although several biomarkers of different nature have been studied from different locations and related to different outcomes, relatively few have reached clinical use. Discovering a protein biomarker that may predict joint damage at an early stage would be helpful in making clinical decisions on the most appropriate treatment regimen for distinct patients. A clinically useful marker, i.e. levels of nitroxidized-AGE-albumin formed by the simultaneous action of dicarbonyls/OONO-, may serve as an authentic tool. Nitroxidized-AGEalbumin level (or serum autoantibodies against nitroxidized-AGE-albumin) paves the path for early diagnoses of RA.

\section{Declaration of conflicting interests}

The authors declared no conflicts of interest with respect to the authorship and/or publication of this article.

\section{Funding}

Akhlas Tarannum is in receipt of fellowship from Council of Scientific \& Industrial Research, New Delhi, (grant no. 09/112/(0560)/2017-EMR-I).

\section{REFERENCES}

1. McInnes IB, Schett $G$. The pathogenesis of rheumatoid arthritis. N Engl J Med 2011;365:2205-19.

2. Hitchon CA, El-Gabalawy HS. Oxidation in rheumatoid arthritis. Arthritis Res Ther 2004;6:265-78.

3. Nienhuis RL, Mandema E. A new serum factor in patients with rheumatoid arthritis; the antiperinuclear factor. Ann Rheum Dis 1964;23:302-5.

4. Young BJ, Mallya RK, Leslie RD, Clark CJ, Hamblin TJ. Anti-keratin antibodies in rheumatoid arthritis. Br Med J 1979;2:97-9.

5. Ungurianu A, Margina D, Gradinaru D, Bacanu C, Ilie M, Tsitsimpikou C, et al. Lipoprotein redox status evaluation as a marker of cardiovascular disease risk in patients with inflammatory disease. Mol Med Rep 2017;15:256-62.

6. Gabriel SE, Michaud K. Epidemiological studies in incidence, prevalence, mortality, and comorbidity of the rheumatic diseases. Arthritis Res Ther 2009;11:229.

7. Ling S, Cheng A, Pumpens P, Michalak M, Holoshitz $\mathrm{J}$. Identification of the rheumatoid arthritis shared epitope binding site on calreticulin. PLoS One 2010;5:11703. 
8. Kobayashi S, Momohara S, Kamatani N, Okamoto H. Molecular aspects of rheumatoid arthritis: role of environmental factors. FEBS J 2008;275:4456-62.

9. Chuang KJ, Chan CC, Su TC, Lee CT, Tang CS. The effect of urban air pollution on inflammation, oxidative stress, coagulation, and autonomic dysfunction in young adults. Am J Respir Crit Care Med 2007;176:370-6.

10. Ozkan Y, Yardym-Akaydyn S, Sepici A, Keskin E, Sepici V, Simsek B. Oxidative status in rheumatoid arthritis. Clin Rheumatol 2007;26:64-8.

11. Ljubuncic P, Gochman E, Reznic AZ. Nitrosative stress in aging-its importance and biological implications in NF-kB signaling. In: Bondy S, Maiese $\mathrm{K}$, editors. Oxidative stress in applied basic research and clinical practice. New York: Humana Press; 2010. p. 27-54.

12. Baynes JW, Thorpe SR. Glycoxidation and lipoxidation in atherogenesis. Free Radic Biol Med 2000;28:1708-16.

13. Peters TJ. All about albumin. Biochemistry, genetics, and medical applications. San Diego: Academic Press; 1996.

14. Bourdon E, Blache D. The importance of proteins in defense against oxidation. Antioxid Redox Signal 2001;3:293-311.

15. Cross CE, van der Vliet A, O'Neill CA, Louie S, Halliwell B. Oxidants, antioxidants, and respiratory tract lining fluids. Environ Health Perspect 1994;102:185-91.

16. Gutteridge JM. Antioxidant properties of the proteins caeruloplasmin, albumin and transferrin. A study of their activity in serum and synovial fluid from patients with rheumatoid arthritis. Biochim Biophys Acta 1986;869:119-27.

17. Carballal S, Radi R, Kirk MC, Barnes S, Freeman BA, Alvarez B. Sulfenic acid formation in human serum albumin by hydrogen peroxide and peroxynitrite. Biochemistry 2003;42:9906-14.

18. Bourdon E, Loreau N, Lagrost L, Blache D. Differential effects of cysteine and methionine residues in the antioxidant activity of human serum albumin. Free Radic Res 2005;39:15-20.

19. Berlett BS, Stadtman ER. Protein oxidation in aging, disease, and oxidative stress. $\mathrm{J}$ Biol Chem 1997;272:20313-6.

20. Clark R, Kupper T. Old meets new: the interaction between innate and adaptive immunity. $\mathrm{J}$ Invest Dermatol 2005;125:629-37.

21. Mittal M, Siddiqui MR, Tran K, Reddy SP, Malik AB. Reactive oxygen species in inflammation and tissue injury. Antioxid Redox Signal 2014;20:1126-67.

22. Paula FS, Alves JD. Non-tumor necrosis factor-based biologic therapies for rheumatoid arthritis: present, future, and insights into pathogenesis. Biologics 2014;8:1-12.

23. Schellekens GA, de Jong BA, van den Hoogen $\mathrm{FH}$, van de Putte LB, van Venrooij WJ. Citrulline is an essential constituent of antigenic determinants recognized by rheumatoid arthritis-specific autoantibodies. J Clin Invest 1998;101:273-81.

24. Hori S, Nomura T, Sakaguchi S. Control of regulatory $\mathrm{T}$ cell development by the transcription factor Foxp3. Science 2003;299:1057-61.

25. Griffith B, Pendyala S, Hecker L, Lee PJ, Natarajan $\mathrm{V}$, Thannickal VJ. NOX enzymes and pulmonary disease. Antioxid Redox Signal 2009;11:2505-16.

26. Bashir S, Harris G, Denman MA, Blake DR, Winyard PG. Oxidative DNA damage and cellular sensitivity to oxidative stress in human autoimmune diseases. Ann Rheum Dis 1993;52:659-66.

27. Filippin LI, Vercelino R, Marroni NP, Xavier RM. Redox signalling and the inflammatory response in rheumatoid arthritis. Clin Exp Immunol 2008;152:415-22.

28. Mateen S, Moin S, Khan AQ, Zafar A, Fatima N. Increased Reactive Oxygen Species Formation and Oxidative Stress in Rheumatoid Arthritis. PLoS One 2016;11:e0152925.

29. Khojah HM, Ahmed S, Abdel-Rahman MS, Hamza $\mathrm{AB}$. Reactive oxygen and nitrogen species in patients with rheumatoid arthritis as potential biomarkers for disease activity and the role of antioxidants. Free Radic Biol Med 2016;97:285-291.

30. Dröge W. Free radicals in the physiological control of cell function. Physiol Rev 2002;82:47-95.

31. Muller FL, Liu Y, Van Remmen H. Complex III releases superoxide to both sides of the inner mitochondrial membrane. $\mathrm{J}$ Biol Chem 2004;279:49064-73.

32. Bauerová K, Bezek A. Role of reactive oxygen and nitrogen species in etiopathogenesis of rheumatoid arthritis. Gen Physiol Biophys 1999;18:15-20.

33. Halliwell B, Gutteridge JM. Free radicals in biology and medicine. New York: Oxford University Press; 2015.

34. Radi R, Peluffo G, Alvarez MN, Naviliat M, Cayota A. Unraveling peroxynitrite formation in biological systems. Free Radic Biol Med 2001;30:463-88.

35. Ischiropoulos H, Zhu L, Beckman JS. Peroxynitrite formation from macrophage-derived nitric oxide. Arch Biochem Biophys 1992;298:446-51.

36. Rubbo H, Radi R, Trujillo M, Telleri R, Kalyanaraman $\mathrm{B}$, Barnes $\mathrm{S}$, et al. Nitric oxide regulation of superoxide and peroxynitrite-dependent lipid peroxidation. Formation of novel nitrogen-containing oxidized lipid derivatives. J Biol Chem 1994;269:26066-75.

37. Naidu BV, Fraga C, Salzman AL, Szabo C, Verrier $\mathrm{ED}$, Mulligan MS. Critical role of reactive nitrogen species in lung ischemia-reperfusion injury. J Heart Lung Transplant 2003;22:784-93.

38. Koppenol WH, Moreno JJ, Pryor WA, Ischiropoulos $\mathrm{H}$, Beckman JS. Peroxynitrite, a cloaked oxidant formed by nitric oxide and superoxide. Chem Res Toxicol 1992;5:834-42. 
39. Salgo MG, Bermúdez E, Squadrito GL, Pryor WA. Peroxynitrite causes DNA damage and oxidation of thiols in rat thymocytes [corrected]. Arch Biochem Biophys 1995;322:500-5.

40. Radi R, Beckman JS, Bush KM, Freeman BA. Peroxynitrite oxidation of sulfhydryls. The cytotoxic potential of superoxide and nitric oxide. J Biol Chem 1991;266:4244-50.

41. Szabó C, Ohshima H. DNA damage induced by peroxynitrite: subsequent biological effects. Nitric Oxide 1997;1:373-85.

42. Beckmann JS, Ye YZ, Anderson PG, Chen J, Accavitti MA, Tarpey MM, et al. Extensive nitration of protein tyrosines in human atherosclerosis detected by immunohistochemistry. Biol Chem Hoppe Seyler 1994;375:81-8.

43. Hubbard SR, Till JH. Protein tyrosine kinase structure and function. Annu Rev Biochem 2000;69:373-98.

44. Mapp PI, Klocke R, Walsh DA, Chana JK, Stevens CR, Gallagher PJ, et al. Localization of 3-nitrotyrosine to rheumatoid and normal synovium. Arthritis Rheum 2001;44:1534-9.

45. Salvemini D, Doyle TM, Cuzzocrea S. Superoxide, peroxynitrite and oxidative/nitrative stress in inflammation. Biochem Soc Trans 2006;34:965-70.

46. Bar-Shai M, Reznick AZ. Reactive nitrogen species induce nuclear factor-kappaB-mediated protein degradation in skeletal muscle cells. Free Radic Biol Med 2006;40:2112-25.

47. de Groot L, Hinkema H, Westra J, Smit AJ, Kallenberg CG, Bijl M, et al. Advanced glycation endproducts are increased in rheumatoid arthritis patients with controlled disease. Arthritis Res Ther 2011;13:205.

48. Drinda S, Franke S, Canet CC, Petrow P, Bräuer R, Hüttich $C$, etal. Identification of the advancedglycation end products $\mathrm{N}$ (epsilon)-carboxymethyllysine in the synovial tissue of patients with rheumatoid arthritis. Ann Rheum Dis 2002;61:488-92.

49. Reddy VP, Beyaz A. Inhibitors of the Maillard reaction and AGE breakers as therapeutics for multiple diseases. Drug Discov Today 2006;11:646-54.

50. Chavakis T, Bierhaus A, Nawroth PP. RAGE (receptor for advanced glycation end products): a central player in the inflammatory response. Microbes Infect 2004;6:1219-25.

51. Moser B, Wendt TM, Ankersmit JH, Hofmann M, Bucciarelli LG, Hudson BI, et al. Blockade of receptor for age (RAGE) suppresses $\mathrm{T}$ lymphocyte proliferation in mixed lymphocyte culture. J Heart Lung Transplant 2003;22:S100.

52. Peterszegi G, Molinari J, Ravelojaona V, Robert L. Effect of advanced glycation end-products on cell proliferation and cell death. Pathol Biol (Paris) 2006;54:396-404.

53. Zhang H, Park Y, Wu J, Chen Xp, Lee S, Yang J, et al. Role of TNF-alpha in vascular dysfunction. Clin Sci (Lond) 2009;116:219-30.
54. Donato R, Sorci G, Riuzzi F, Arcuri C, Bianchi R, Brozzi $F$, et al. S100B's double life: intracellular regulator and extracellular signal. Biochim Biophys Acta 2009;1793:1008-22.

55. Scheuren N, Jacobs M, Ertl G, Schorb W. Cyclooxygenase-2 in myocardium stimulation by angiotensin-II in cultured cardiac fibroblasts and role at acute myocardial infarction. $\mathrm{J}$ Mol Cell Cardiol 2002;34:29-37.

56. Dimopoulos N, Piperi C, Psarra V, Lea RW, Kalofoutis A. Increased plasma levels of 8-isoPGF2alpha and IL-6 in an elderly population with depression. Psychiatry Res 2008;161:59-66.

57. Ishihara K, Tsutsumi K, Kawane S, Nakajima $\mathrm{M}$, Kasaoka T. The receptor for advanced glycation end-products (RAGE) directly binds to ERK by a D-domain-like docking site. FEBS Lett 2003;550:107-13.

58. Origlia N, Righi M, Capsoni S, Cattaneo A, Fang F, Stern DM, et al. Receptor for advanced glycation end product-dependent activation of p38 mitogenactivated protein kinase contributes to amyloid-betamediated cortical synaptic dysfunction. J Neurosci 2008;28:3521-30.

59. Ito S, Sawada M, Haneda M, Fujii S, Oh-Hashi K, Kiuchi K, et al. Amyloid-beta peptides induce cell proliferation and macrophage colony-stimulating factor expression via the PI3-kinase/Akt pathway in cultured $\mathrm{Ra} 2$ microglial cells. FEBS Lett 2005;579:1995-2000.

60. Cobb MH. MAP kinase pathways. Prog Biophys Mol Biol 1999;71:479-500.

61. Bierhaus A, Konrade I, Haag GM, et al. The receptor RAGE regulates glyoxalase-1 transcription, expression and activity. Diabetologia 2005;48:90

62. Xue M, Rabbani N, Momiji H, Imbasi P, Anwar MM, Kitteringham N, et al. Transcriptional control of glyoxalase 1 by Nrf2 provides a stress-responsive defence against dicarbonyl glycation. Biochem $\mathrm{J}$ 2012;443:213-22.

63. Jung $\mathrm{T}$, Catalgol $\mathrm{B}$, Grune $\mathrm{T}$. The proteasomal system. Mol Aspects Med 2009;30:191-296.

64. Varga ZV, Giricz Z, Liaudet L, Haskó G, Ferdinandy $\mathrm{P}$, Pacher P. Interplay of oxidative, nitrosative/ nitrative stress, inflammation, cell death and autophagy in diabetic cardiomyopathy. Biochim Biophys Acta 2015;1852:232-42.

65. Tamura Y, Adachi H, Osuga J, Ohashi K, Yahagi N, Sekiya M, et al. FEEL-1 and FEEL-2 are endocytic receptors for advanced glycation end products. J Biol Chem 2003;278:12613-7.

66. Yan X, Wu Xiao C, Sun M, Tsang BK, Gibb W. Nuclear factor kappa B activation and regulation of cyclooxygenase type-2 expression in human amnion mesenchymal cells by interleukin-1beta. Biol Reprod 2002;66:1667-71.

67. Aruoma OI. Free radicals, antioxidants and international nutrition. Asia Pac J Clin Nutr 1999;8:53-63. 
68. Dalle-Donne I, Rossi R, Colombo R, Giustarini $\mathrm{D}$, Milzani A. Biomarkers of oxidative damage in human disease. Clin Chem 2006;52:601-23.

69. Mallikarjunappa S, Prakash M. Mallikarjunappa S, Prakash M. Urine protein thiols in chronic renal failure patients. Indian J Nephrol 2007;17:7.

70. Brot $\mathrm{N}$, Weissbach $\mathrm{H}$. The biochemistry of methionine sulfoxide residues in proteins. Trends Biochem Sci 1982;7:137-9.

71. Kokkola R, Sundberg E, Ulfgren AK, Palmblad K, Li J, Wang $\mathrm{H}$, et al. High mobility group box chromosomal protein 1: a novel proinflammatory mediator in synovitis. Arthritis Rheum 2002;46:2598-603.

72. Basta G, Lazzerini G, Massaro M, Simoncini T, Tanganelli P, Fu C, et al. Advanced glycation end products activate endothelium through signaltransduction receptor RAGE: a mechanism for amplification of inflammatory responses. Circulation 2002;105:816-22.

73. Miyata T, Ishiguro N, Yasuda Y, Ito T, Nangaku M, Iwata $\mathrm{H}$, et al. Increased pentosidine, an advanced glycation end product, in plasma and synovial fluid from patients with rheumatoid arthritis and its relation with inflammatory markers. Biochem Biophys Res Commun 1998;244:45-9.

74. Requena JR, Fu MX, Ahmed MU, Jenkins AJ, Lyons TJ, Thorpe SR. Lipoxidation products as biomarkers of oxidative damage to proteins during lipid peroxidation reactions. Nephrol Dial Transplant 1996;11:48-53.

75. Wells-Knecht KJ, Zyzak DV, Litchfield JE, Thorpe SR, Baynes JW. Mechanism of autoxidative glycosylation: identification of glyoxal and arabinose as intermediates in the autoxidative modification of proteins by glucose. Biochemistry 1995;34:3702-9.

76. Niwa T, Katsuzaki T, Momoi T, Miyazaki T, Ogawa $\mathrm{H}$, Saito A, et al. Modification of beta $2 \mathrm{~m}$ with advanced glycation end products as observed in dialysis-related amyloidosis by 3-DG accumulating in uremic serum. Kidney Int 1996;49:861-7.

77. Miyazawa N, Abe M, Souma T, Tanemoto M, Abe $\mathrm{T}$, Nakayama $\mathrm{M}$, et al. Methylglyoxal augments intracellular oxidative stress in human aortic endothelial cells. Free Radic Res 2010;44:101-7.

78. Schleicher ED, Wagner E, Nerlich AG. Increased accumulation of the glycoxidation product N(epsilon)(carboxymethyl)lysine in human tissues in diabetes and aging. J Clin Invest 1997;99:457-68.

79. Wells-Knecht KJ, Brinkmann E, Wells-Knecht MC, Litchfield JE, Ahmed MU, Reddy S, et al. New biomarkers of Maillard reaction damage to proteins. Nephrol Dial Transplant 1996;11:41-7.

80. Nagai R, Unno Y, Hayashi MC, Masuda S, Hayase $\mathrm{F}$, Kinae $\mathrm{N}$, et al. Peroxynitrite induces formation of $\mathrm{N}$ ( epsilon )-(carboxymethyl) lysine by the cleavage of Amadori product and generation of glucosone and glyoxal from glucose: novel pathways for protein modification by peroxynitrite. Diabetes 2002;51:2833-9.
81. Liu H, Yu S, Xu W, Xu J. Enhancement of $26 \mathrm{~S}$ proteasome functionality connects oxidative stress and vascular endothelial inflammatory response in diabetes mellitus. Arterioscler Thromb Vasc Biol 2012;32:2131-40.

82. Halliwell B. Reactive oxygen species in living systems: source, biochemistry, and role in human disease. Am J Med 1991;91:14-22.

83. Sies $\mathrm{H}$. Role of reactive oxygen species in biological processes. Klin Wochenschr 1991;69:965-8.

84. Thornalley PJ. Glyoxalase I--structure, function and a critical role in the enzymatic defence against glycation. Biochem Soc Trans 2003;31:1343-8.

85. Thornalley PJ. The enzymatic defence against glycation in health, disease and therapeutics: a symposium to examine the concept. Biochem Soc Trans 2003;31:1341-2.

86. Paredes S, Girona J, Hurt-Camejo E, Vallve JC, Olive S, Heras $\mathrm{M}$, et al. Antioxidant vitamins and lipid peroxidation in patients with rheumatoid arthritis: association with inflammatory markers. J Rheumatol 2002;29:2271-7.

87. García-González A, Gaxiola-Robles R, ZentenoSavín T. Oxidative stress in patients with rheumatoid arthritis. Rev Invest Clin 2015;67:46-53.

88. Cedergren J, Forslund T, Sundquist T, Skogh T. Intracellular oxidative activation in synovial fluid neutrophils from patients with rheumatoid arthritis but not from other arthritis patients. J Rheumatol 2007;34:2162-70.

89. Ali AM, Habeeb RA, El-Azizi NO, Khattab DA, Abo-Shady RA, Elkabarity RH. Higher nitric oxide levels are associated with disease activity in Egyptian rheumatoid arthritis patients. Rev Bras Reumatol 2014;54: 446-51.

90. Gringhuis SI, Leow A, Papendrecht-Van Der Voort EA, Remans PH, Breedveld FC, Verweij CL. Displacement of linker for activation of $T$ cells from the plasma membrane due to redox balance alterations results in hyporesponsiveness of synovial fluid $\mathrm{T}$ lymphocytes in rheumatoid arthritis. J Immunol 2000;164:2170-9.

91. Dean RT, Fu S, Stocker R, Davies MJ. Biochemistry and pathology of radical-mediated protein oxidation. Biochem J 1997;324:1-18.

92. Neelofar K, Arif Z, Ahmad J, Alam K. Nonenzymatic glucosylation induced neo-epitopes on human serum albumin: A concentration based study. PLoS One 2017;12:e0172074.

93. Michaëlsson E, Broddefalk J, Engström A, Kihlberg $\mathrm{J}$, Holmdahl R. Antigen processing and presentation of a naturally glycosylated protein elicits major histocompatibility complex class II-restricted, carbohydrate-specific $\mathrm{T}$ cells. Eur $\mathrm{J}$ Immunol 1996;26:1906-10.

94. Chen JR, Takahashi M, Suzuki M, Kushida $\mathrm{K}$, Miyamoto $\mathrm{S}$, Inoue $\mathrm{T}$. Comparison of the concentrations of pentosidine in the synovial 
fluid, serum and urine of patients with rheumatoid arthritis and osteoarthritis. Rheumatology (Oxford) 1999;38:1275-8.

95. Takahashi M, Kushida K, Ohishi T, Kawana K, Hoshino H, Uchiyama A, et al. Quantitative analysis of crosslinks pyridinoline and pentosidine in articular cartilage of patients with bone and joint disorders. Arthritis Rheum 1994;37:724-8.

96. McCord JM. Free radicals and inflammation: protection of synovial fluid by superoxide dismutase. Science 1974;185:529-31.

97. Kaur H, Halliwell B. Evidence for nitric oxidemediated oxidative damage in chronic inflammation. Nitrotyrosine in serum and synovial fluid from rheumatoid patients. FEBS Lett 1994;350:9-12.

98. Islam S, Moinuddin, Mir AR, Raghav A, Habib S, Alam K, et al. Glycation, oxidation and glycoxidation of IgG: a biophysical, biochemical, immunological and hematological study. J Biomol Struct Dyn 2018;36:2637-2653.

99. Thornalley PJ, Battah S, Ahmed N, Karachalias N, Agalou S, Babaei-Jadidi R, et al. Quantitative screening of advanced glycation endproducts in cellular and extracellular proteins by tandem mass spectrometry. Biochem J 2003;375:581-92.

100. Kobayashi M, Li L, Iwamoto N, Nakajima-Takagi Y, Kaneko H, Nakayama Y, et al. The antioxidant defense system Keap1-Nrf2 comprises a multiple sensing mechanism for responding to a wide range of chemical compounds. Mol Cell Biol 2009;29:493-502.

101. Wruck CJ, Fragoulis A, Gurzynski A, Brandenburg LO, Kan YW, Chan K, et al. Role of oxidative stress in rheumatoid arthritis: insights from the Nrf2knockout mice. Ann Rheum Dis 2011;70:844-50.

102. Cohen MP. Intervention strategies to prevent pathogenetic effects of glycated albumin. Arch Biochem Biophys 2003;419:25-30.

103. Arif Z, Neelofar K, Tarannum A, Arfat MY, Ahmad S, Zaman A, et al. SLE autoantibodies are well recognized by peroxynitrite-modified-HSA: Its implications in the pathogenesis of SLE. Int $\mathrm{J}$ Biol Macromol 2018;106:1240-9.

104. Kurien BT, Scofield RH. Autoimmunity and oxidatively modified autoantigens. Autoimmun Rev 2008;7:567-73.

105. Arif Z, Arfat MY, Ahmad J, Zaman A, Islam SN, Khan MA. Relevance of nitroxidation of albumin in rheumatoid arthritis: A biochemical and clinical study. J Clin Cell Immunol 2015;6:324.

106. Arif Z, Arfat MY, Neelofar K, Ahmad S, Badar A, Khan MA, et al. Effect of peroxynitrite on human serum albumin: a multi technique approach. J Biomol Struct Dyn 2017;35:2066-76. 